\title{
Relato de Projeto para Disseminação e Apoio à Participação de Mulheres em Áreas da Ciência
}

\author{
Ana Luiza S. Milson ${ }^{1}$, Luísa M. Laboissiere ${ }^{1}$, \\ Marcella D. Ferreira ${ }^{1}$, Rodrigo Cardoso ${ }^{1}$, Michele A. Brandão ${ }^{1}$ \\ ${ }^{1}$ Instituto Federal de Minas Gerais \\ Ribeirão das Neves - MG \\ \{luisamarqueslaboissiere, cela.ferreira2009,milson109asaph\}@gmail.com, \\ rodrigo.cardoso1007@gmail.com, michele.brandao@ifmg.edu.br
}

\begin{abstract}
DAMA project aims to support female participation in areas of technology and science. The project performed several actions to help girls feel welcomed in areas considered masculine and to show that there is space for them, in addition to contributing to the personal and professional growth of the members. This article describes the main actions developed in the project and their results.
\end{abstract}

Resumo. O projeto DAMA objetiva apoiar a participação feminina em áreas de tecnologia e ciência. Diversas ações foram realizadas para ajudar meninas a se sentirem acolhidas em áreas consideradas masculinas e mostrar que há espaço para elas, além de contribuir para o crescimento pessoal e profissional das integrantes. Este artigo descreve as principais ações desenvolvidas no projeto e seus resultados.

\section{Introdução}

Estatísticas do INEP (Instituto Nacional de Estudos e Pesquisas Educacionais Anísio Teixeira) do ano de 2019, publicadas em 2020, mostram um aumento no número de mulheres ingressando e concluindo a graduação, maior que a quantidade de homens. Entretanto, segundo o IBGE (Instituto Brasileiro de Geografia e Estatística), mesmo as mulheres sendo a maioria com ensino superior, elas ainda ganham menos que os homens ${ }^{1}$

Além do desenvolvimento de políticas públicas que contribuem para a redução de desigualdades e o aumento do apoio a grupos minoritários, iniciativas que ampliem o acesso e a divulgação de informações também podem ser uma solução. Especialmente, se forem consideradas a baixa presença feminina em áreas consideradas "masculinas", que podem ser muito beneficiadas com a diversidade entre os profissionais. Uma das razões para existirem poucas mulheres nessas áreas é a falta de incentivo e informações adequadas para mitigar preconceitos e estereótipos que há muitos anos vem sendo disseminados [Silva 2012, Sampaio et al. 2020].

Esse cenário contribuiu para a idealização e motivação do projeto DAMA, cujo objetivo principal é estimular, atrair e apoiar a participação feminina nas ciências e tecnologia. De fato, foram realizadas várias ações para alcançar os objetivos, principalmente,

\footnotetext{
${ }^{1}$ IBGE - mulheres ganham menos que homens mesmo sendo maioria com ensino superior: https://agenciabrasil.ebc.com.br/geral/noticia/2018-03/ ibge-mulheres-ganham-menos-que-homens-mesmo-sendo-maioria-com-ensino-superior. Acessado em 26 de março de 2021.
} 
com o auxílio da rede social Instagram. Foi criado um perfil do projeto e nele foram postados e divulgados tais realizações. Entre elas, tem-se mini tutoriais, depoimentos de mulheres negras em áreas de STEM (Science, Technology, Engineering and Mathematics ou Ciência, Tecnologia, Engenharia e Matemática, em português), concurso de redação, mesa-redonda, entre outros. Essa rede social esteve atualizada em todo o processo, visando alcançar mais pessoas e divulgar oportunidades e notícias.

Vale destacar que o projeto DAMA foi realizado em parceria com outros dois projetos de extensão, chamados BitGirls e Jogando para Desmistificar: Difusão de Informações sobre Mulheres nas Ciências de forma Lúdica. Neste artigo, apresentamos o projeto DAMA, bem como descrevemos suas ações e resultados alcançados.

Trabalhos relacionados. Há iniciativas como o Tech Ladies que atuam como uma rede de empoderamento feminino na tecnologia [Souza et al. 2017]. Esse projeto objetiva aumentar a participação feminina no mercado tecnológico por meio de inovação tecnológica e empreendedorismo. Complementarmente, relatórios da National Academy of Science fazem uma série de recomendações para que sejam feitas intervenções em faculdades e universidades para melhorar e ampliar a participação de mulheres na ciência, engenharia e medicina [National Academies of Sciences et al. 2020]. De maneira geral, pode-se notar em diversos setores da sociedade, uma mudança no sentido de incentivar e contribuir com o empoderamento feminino e a presença de mulheres nas mais diversas áreas. Por exemplo, o tradicional jogo de tabuleiro Monopoly lançou em setembro de 2019 uma versão feminina, chamada Ms. Monopoly, como uma maneira de estimular o empoderamento econômico das mulheres ${ }^{2}$. Entretanto, ainda há um caminho longo a ser percorrido.

\section{Ações Realizadas}

O projeto DAMA, inicialmente, objetivou atrair mulheres para a área de ciência da computação, mas ao longo de seu desenvolvimento, buscou-se atrair mulheres para as áreas de STEM. Para isso, foram realizadas diversas atividades, descritas aqui cronologicamente. É importante destacar que todas as atividades foram realizadas de forma remota devido à pandemia do novo coronavírus.

Em abril de 2020, foi iniciado o desenvolvimento de um jogo da memória para o website Elas na Ciência. Também foi possível participar da escrita de um artigo para o Women in Information Technology (WIT) (Elas na Ciência: Website com Jogos para Divulgar Personalidades Femininas [Milson et al. 2020]) e elaboração de um vídeo para a conferência WI-SCI, em parceria com bolsistas do projeto Bytes \& Elas. Essas atividades foram importantes para o desenvolvimento pessoal e profissional das integrantes do projeto. Já em maio de 2020, foi realizado um curso de introdução a HTML/CSS pela plataforma Khan Academy ${ }^{3}$. Nesse mesmo mês, foi iniciado um Concurso de Redação, em parceria com o Curso de Redação do Instituto Federal de Minas Gerais campus Ribeirão das Neves. Além disso, foi criado um perfil na rede social Instagram (@projeto_dama)

Em junho de 2020, iniciou-se o planejamento de um projeto com o objetivo: buscar mulheres negras na área da STEM, para relatarem suas experiências e vivências, a fim

\footnotetext{
${ }^{2}$ Jogos que empoderam: https://gente.globo.com/jogos-que-empoderam/\#: :

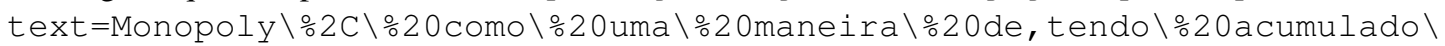
$\div 200 \backslash \% 20$ maior $\ 20$ patrim $\ \mathrm{C} 3 \backslash \% \mathrm{~B} 4 \mathrm{ni}$... Acessado em 26 de março de 2021

${ }^{3}$ Khan Academy: https://www. khanacademy .org/
} 
de colaborar com a representatividade e, de certa maneira, gerar uma rede de apoio. Nesse mesmo mês, foram selecionadas, por meio de um convite, mulheres pretas para que seus relatos fossem postados no Instagram, no perfil do projeto, de acordo com um roteiro. Em seguida, em julho de 2020, o trabalho "Mulheres Negras na STEM" foi divulgado.

No mês de agosto de 2020, foi retomada da ideia do Concurso de Redação, que foi realizado em maio, para colaborar com a correção das redações finalistas e divulgação dos ganhadores. Para os três primeiros colocados, foi realizada a entrega de medalhas e de certificados. Em setembro de 2020, foram realizadas melhorias no website Elas na Ciência para divulgação de personalidades femininas e no jogo da memória. Nessa perspectiva, ambos foram realizados em parceria com o projeto Bytes \& Elas.

Já em outubro de 2020, uma nova atividade foi idealizada, a elaboração de "Mini Tutoriais", que consistiu na postagem de conteúdos de forma rápida e direta no perfil do projeto no Instagram. Também foram apresentadas as iniciativas do projeto na SNCT 2020 (Semana Nacional Ciência e Tecnologia). Em novembro de 2020, foram divulgados os mini tutoriais sobre CANVA, página HTML e CSS e edição de vídeo. Finalmente, em dezembro de 2020 e janeiro de 2021, uma mesa-redonda foi organizada e realizada com o objetivo de incentivar estudantes do ensino médio a seguirem em áreas de STEM.

\section{Resultados Alcançados}

Durante a realização do projeto, diversos resultados foram obtidos e são descritos nesta seção.

Jogo da memória. A Figura 1 apresenta o jogo da memória desenvolvido em abril de 2020, o qual possui como objetivo principal passar aos jogadores conhecimentos sobre seis mulheres importantes para a Computação. Tal jogo foi desenvolvido de forma simples com 12 cartas, sendo 6 delas imagem de mulheres e as outras 6 , informações correspondentes a essas mulheres. Isso difere da tradicional forma desse tipo de jogo, que geralmente contém duas imagens iguais. Isso foi desenvolvido com o intuito de levar um aprendizado maior, pois o jogador terá que ler as informações contidas na carta e relacioná-la à foto encontrada na outra carta. Entretanto, pensando em um melhor aprendizado, foi adicionado à carta, uma pequena foto da cientista - o que em algumas cartas são até diferentes das imagens correspondentes - para que, dessa forma, o jogador não fique perdido e saiba relacionar uma carta à outra corretamente. Dessa forma, além de levar o conhecimento e a representatividade dessas mulheres, o mini jogo da memória também contribuiu para o conhecimento de suas integrantes ao colocarem em prática seus aprendizados de HTML, CSS e JavaScript.

Vídeo para WI-SCI. Em parceria com o projeto BitGirls, foi produzido um vídeo ${ }^{4}$ para a $1^{\circ}$ WI-SCI, realizado pelo Instituto Federal do Norte de Minas Gerais (IFNMG). Tal vídeo explica a necessidade de projetos como esse e possui relatos das integrantes sobre a experiência no projeto, uma grande oportunidade de acolhida para seguirem nessa área.

Concurso de redação. A Figura 1 apresenta o Concurso de Redação em parceria com o Curso de Redação do IFMG. O tema proposto foi "A Inserção das Mulheres na Ciência Brasileira”, contando com a participação de 337 discentes. Essa iniciativa tornou possível

${ }^{4}$ Link para o vídeo: https: //www.youtube. com/watch?v=wlYc5xIk45Q. 


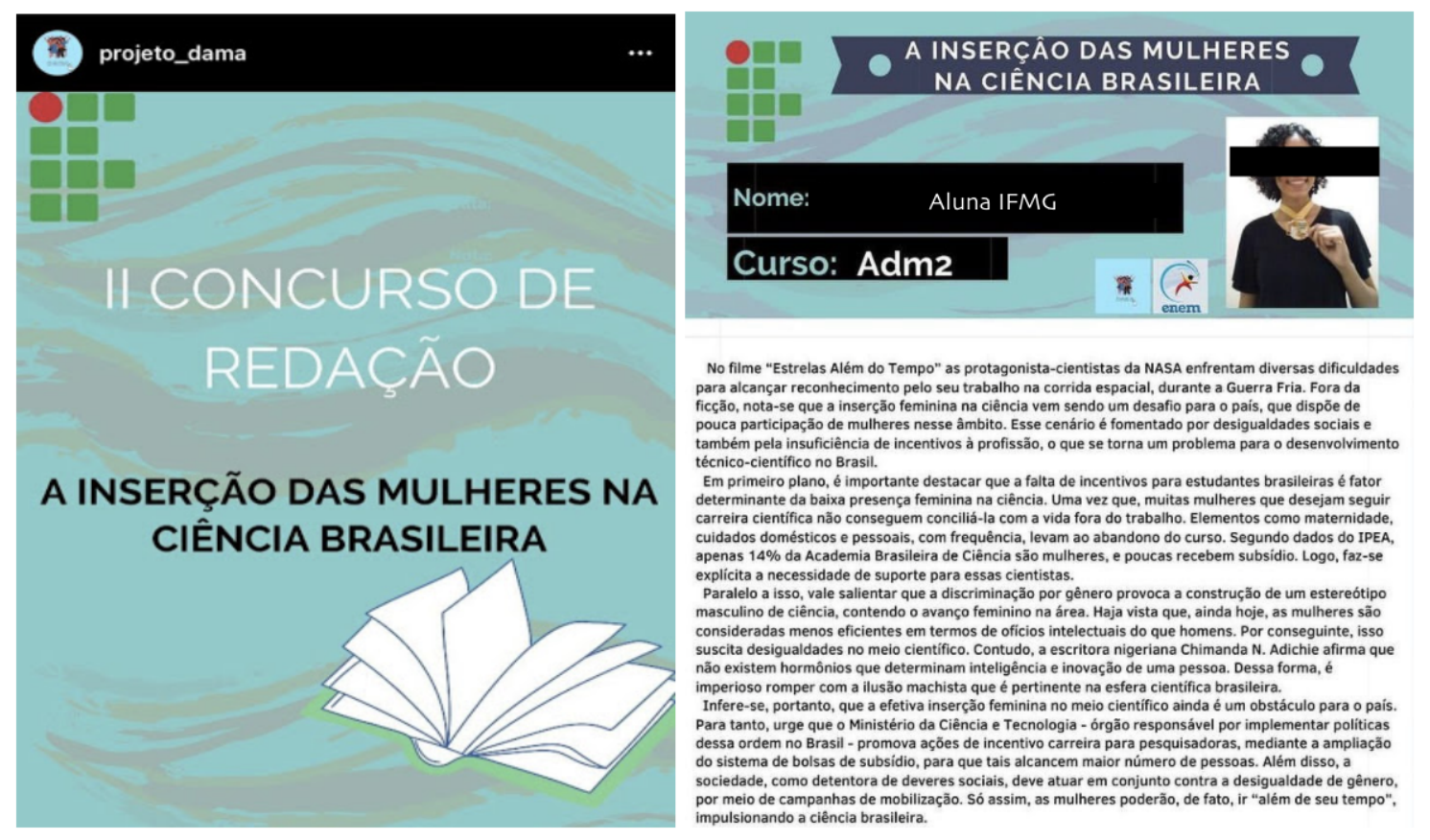

Figura 1. Concurso de Redação cadastrado como evento de extensão.

levantar a reflexão desse assunto entre os participantes, alertando sobre a discrepância entre homens e mulheres existente na ciência.

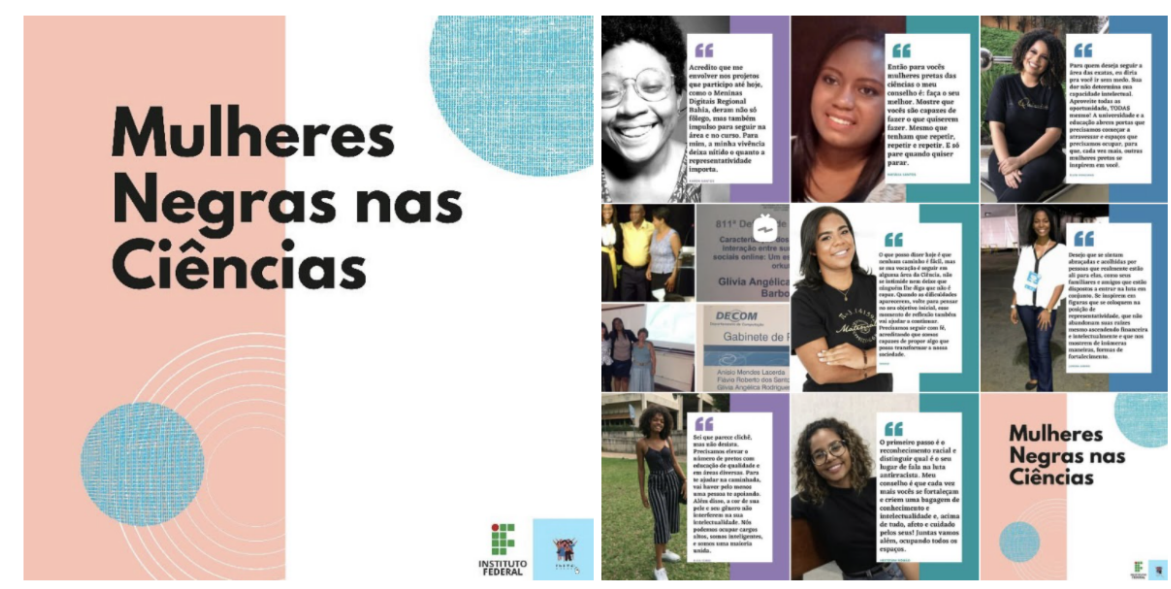

Figura 2. Mulheres Negras em áreas da STEM.

Mulheres negras em áreas de STEM. A Figura 2 apresenta a iniciativa "Mulheres negras em áreas de STEM" (tema mais detalhado foi "Incentivos, Desafios e Superações de Mulheres Negras em áreas das Ciências STEM"). Foram selecionadas nove mulheres para relatarem suas experiências como negras e mulheres em áreas da ciência em seus cursos técnicos e de graduação. As mulheres deixaram uma frase de incentivo para meninas/mulheres que desejam seguir nesse ramo. Os textos foram publicados no perfil do projeto no Instagram e obteve um total, aproximadamente de 30 comentários positivos e 465 likes nas publicações.

Mesa-redonda. O evento "Mesa-redonda: Experiências em cursos técnicos nas áreas 
de STEM" aconteceu em janeiro de 2021, contou com a participação de 26 discentes e foram partilhados relatos e experiências de 5 meninas. As perguntas que guiaram a mesaredonda foram: "O que são as áreas de STEM? Exemplificar com cursos."; "Quais foram os principais desafios enfrentados nessa área?"; "O que te incentivou a escolher o curso na área de STEM?"; e "Você já se sentiu desmotivada a medida do curso? Por que?".

Finalmente, o projeto também contribuiu para a permanência de suas integrantes nos cursos técnicos em informática, que relatam já terem se sentido desmotivadas nessa área. Entretanto, com as realizações do projeto acabaram por se sentirem apoiadas a persistirem na finalização do curso.

\section{Conclusão}

Neste artigo, foi apresentado o projeto DAMA, suas ações e resultados alcançados. Em geral, objetivou-se disseminar informação, apoiar a participação e atrair mulheres para áreas das ciências e tecnologia. Assim, foram realizadas diversas iniciativas com públicoalvo, principalmente, estudantes do Ensino Médio. Tais feitos foram desenvolvidos por alunas do ensino médio do técnico integrado do IFMG. Além do projeto beneficiar à comunidade, conforme apresentado nos resultados, também contribuiu para a formação das alunas envolvidas no projeto. Finalmente, como trabalhos futuros, planeja-se realizar mais iniciativas que mostrem às meninas que há espaço para elas em áreas de STEM, e em qualquer outro lugar que elas desejarem.

Agradecimentos. Trabalho parcialmente financiado pelo IFMG e pelo Projeto CNPq Bytes \& Elas, 442265/2018-2.

\section{Referências}

Milson, A. L. S., Ribeiro, I. M. C., Andrade, I. A., Gonçalves, J. M., Laboissiere, L. M., Ferreira, M. D., Dalip, D. H., Brandão, M. A., and Moro, M. M. (2020). Elas na ciência: Website com jogos para divulgar personalidades femininas. In Anais do XIV Women in Information Technology, pages 10-19.

National Academies of Sciences, E., Medicine, et al. (2020). Promising practices for addressing the underrepresentation of women in science, engineering, and medicine: Opening doors. National Academies Press.

Sampaio, C. M., Venturini, M. A. D., and dos Anjos Borges, V. (2020). Incentivos à participação feminina na área da ciência da computação. Revista Alomorfia ISSN 25945637, 4(2):25-44.

Silva, F. F. d. (2012). Mulheres na ciência: Vozes, tempos, lugares e trajetórias. Master's thesis.

Souza, A. C., Perkoski, I., Veiga, K., and Romankiv, V. (2017). Relato tech ladies: redes de colaboração entre mulheres na tecnologia. In Anais do XI Women in Information Technology, pages 1181-1185, São Paulo, Brasil. 